\title{
Vigabatrin, a GABA Transaminase Inhibitor, Reversibly Eliminates Tinnitus in an Animal Model
}

\author{
Thomas J. Brozoski, T. Joseph D. Spires, and Carol A. Bauer \\ ${ }^{1}$ Division of Otolaryngology, Southern Illinois University School of Medicine, 801 N. Rutledge St., Rm. 3205 P. O. Box 19629 \\ Springfield, IL 62794-9629, USA
}

Received: 24 August 2006; Accepted: 27 November 2006; Online publication: 13 January 2007

\begin{abstract}
Animal models have facilitated basic neuroscience research investigating the pathophysiology of tinnitus. It has been hypothesized that partial deafferentation produces a loss of tonic inhibition in the auditory system that may lead to inappropriate neuroplastic changes eventually expressed as tinnitus. The pathological down-regulation of $\gamma$-amino butyric acid (GABA) provides a potential mechanism for this loss of inhibition. Using an animal model previously demonstrated to be sensitive to treatments that either induce or attenuate tinnitus, the present study examined the effect of the specific GABA agonist vigabatrin on chronic tinnitus. It was hypothesized that vigabatrin would decrease the evidence of tinnitus by restoring central inhibitory function through increased GABA availability. Vigabatrin has been demonstrated to elevate central GABA levels (Mattson et al. 1995). Tinnitus was induced in rats using a single 1-h unilateral exposure to band-limited noise, which preserved normal hearing in one ear. Psychophysical evidence of tinnitus was obtained using a free-operant conditioned-suppression method: Rats lever-pressed for food pellets and were trained to discriminate between the presence and absence of sound by punishing lever pressing with a mild foot shock $(0.5 \mathrm{~mA} ; 1 \mathrm{~s})$ at the conclusion of randomly introduced silent periods (60 s) inserted into background low-level noise. Additional random
\end{abstract}

Correspondence to: Thomas J. Brozoski • Division of Otolaryngology • Southern Illinois University School of Medicine $\bullet 801$ N. Rutledge St., Rm. 3205 P. O. Box 19629 Springfield, IL 62794-9629, USA. Telephone: +1-217-5456583; email: tbrozoski@siumed.edu insertion of pure tone and noise periods of variable intensity enabled the derivation of psychophysical functions that reflected the presence of tinnitus with features similar to $20-\mathrm{kHz}$ tones. Vigabatrin was chronically administered via drinking water at 30 and $81 \mathrm{mg} \mathrm{kg}^{-1}$ day $^{-1}$, with each dose level tested over 2 weeks, followed by a 0 -mg washout test. Vigabatrin completely and reversibly eliminated the psychophysical evidence of tinnitus at both doses. Although vigabatrin has serious negative side effects that have prevented its clinical use in the USA, it is nevertheless a potentially useful tool in unraveling tinnitus pathophysiology.

Keywords: tinnitus, vigabatrin, GABA, animal model

\section{INTRODUCTION}

Animal models have facilitated basic research into the pathophysiology of tinnitus (Bauer and Brozoski 2001; Bauer et al. 1999b; Brozoski and Bauer 2005; Brozoski et al. 2002; Guitton et al. 2005; Heffner and Koay 2005; Jastreboff 1995; Jastreboff et al. 1988; Kaltenbach and Heffner 1999; Kaltenbach et al. 2004; Lobarinas et al. 2004; Turner et al. 2006) and provide a method for screening compounds (Bauer and Brozoski 2001) potentially useful in treating this disorder. Increased understanding of tinnitus and the development of effective treatments are important for the estimated 10.1 to $14.5 \%$ of the adult population with chronic tinnitus (Cooper 1994; Davis and El Refaie 2000). It has been hypothesized that partial deafferentation from various causes, such as acoustic trauma or age-related hearing loss, produces 
a loss of inhibitory tone in the auditory system. Loss of central inhibition would be expected to significantly alter auditory processing (Brozoski et al. 2002; Caspary et al. 1999; Suneja et al. 1998a; Szczepaniak and Moller 1996; Willott and Lu 1982), which, in turn, could lead to inappropriate neuroplastic changes eventually expressed as a sensation of tinnitus. Because $\gamma$-amino butyric acid (GABA) is a generally inhibitory neurotransmitter found in appreciable amounts at many levels of the central auditory pathway (Backoff et al. 1997; Bauer et al. 2000; Caspary et al. 1995; Milbrandt et al. 1996; Suneja et al. 1998b), a corollary to the loss-of-inhibition and tinnitus hypothesis would be the down-regulation of GABA activity. If the linkage is causal, then elevating GABA function in animals demonstrated to have tinnitus should reduce their tinnitus. Using an animal model of chronic acoustic-trauma-induced tinnitus previously demonstrated to be sensitive to manipulations that either induce (Bauer et al. 1998) or attenuate tinnitus (Bauer and Brozoski 2001), the GABA agonist vigabatrin was given to rats with noiseinduced tinnitus and to controls without tinnitus. Vigabatrin is a selective, irreversible inhibitor of GABA transaminase, the catabolic enzyme for GABA. It was hypothesized that vigabatrin treatment would increase central GABA levels and decrease the psychophysical evidence of tinnitus in rats with tinnitus. It was also hypothesized that the treatment effect would be reversible because the neuroplastic alterations responsible for tinnitus appear to be quite durable (Brozoski and Bauer 2005).

\section{METHOD}

\section{Subjects}

Twenty eight adult male Long-Evans rats, 4 months old at the start of the experiment, were individually housed and maintained at $25^{\circ} \mathrm{C}$ with a $12 / 12 \mathrm{~h}$ reversed light/dark schedule. The experimental protocol was approved by the Laboratory Animal Care and Use Committee of Southern Illinois University School of Medicine. One subject was discarded at the beginning of the experiment because of poor health.

\section{Acoustic exposure and calibration methods}

Fourteen randomly selected subjects were exposed once to loud sound before operant training and predrug testing (Table 1, week 1). These subjects will be referred to as "exposed," in contrast to the control subjects, which will be referred to as "unexposed." All subjects were anesthetized with a ketamine $\mathrm{HCl}(50$ $\mathrm{mg} / \mathrm{kg}$ ) xylazine $(9 \mathrm{mg} / \mathrm{kg})$ mixture, placed in a modified stereotaxic head frame, and had their hearing thresholds determined using acoustic brainstem-evoked potentials (described below). The exposed subjects were then exposed once unilaterally for 60 min to band-limited noise. The exposure stimulus was produced using a precision noise source (HewlettPackard 8057A, Palo Alto, CA, USA), band-pass filtered (Krohn-Hite 3342R, Brockton, MA, USA), amplified (Sony STR-DE135, Sony, New York, NY,

TABLE 1

Experimental time line

\begin{tabular}{|c|c|c|}
\hline \multicolumn{3}{|c|}{ Experimental time line } \\
\hline Time (weeks) & Treatment & Comment \\
\hline 1 & $\begin{array}{l}\text { Exposure to noise and initial ABR threshold } \\
\text { measurement }\end{array}$ & Approx. age: 5 months. Weight range: 380-435 g \\
\hline $2-5$ & Initial shaping and training to lever press & \\
\hline 6 & Stimulus acclimation & Tones vs BBN introduced \\
\hline 7 & Speaker-off suppression training & Speaker-off vs BBN only \\
\hline $8-10$ & Initial discrimination training & \\
\hline $11-13$ & $\begin{array}{l}\text { Discrimination testing and derivation } \\
\text { of psychophysical functions }\end{array}$ & End of period selection of subjects for group membership \\
\hline $14-55$ & Home caged, no testing & Unrestricted diet \\
\hline 56 & Reestablish restricted diet regimen & No testing \\
\hline $57-58$ & Reestablish discrimination performance & Data not used \\
\hline 59-61 & Vigabatrin 0-mg discrimination testing & \\
\hline $62-64$ & Vigabatrin 30-mg discrimination testing & On drug 4 days before testing begins \\
\hline $65-67$ & Vigabatrin $81-\mathrm{mg}$ discrimination testing & Dose established 4 days before testing resumes \\
\hline 67 & $\begin{array}{l}\text { ABR threshold measurement while } \\
\text { on viagabatrin }(81 \mathrm{mg})\end{array}$ & $\begin{array}{l}3 \text { randomly selected unexposed and three randomly } \\
\text { selected exposed subjects }\end{array}$ \\
\hline $68-73$ & Home caged, no drug, no testing & Unrestricted diet \\
\hline 74 & Reestablish restricted diet regimen & No testing \\
\hline $75-77$ & Washout $(0 \mathrm{mg})$ discrimination retest & \\
\hline
\end{tabular}


USA), and delivered monaurally using a speaker driver (Realistic 40-1398, Tandy, Ft. Worth, TX, USA) attached to a cone-shaped speculum that fit tightly into the auditory canal. Peak stimulus intensity, centered at $16.13 \mathrm{kHz}$, was $120 \mathrm{~dB}$ [sound pressure level (SPL)], with an approximately linear decay to ambient levels at 8 and $28 \mathrm{kHz}$. Acoustic values were calibrated using a Brüel \& Kjaer (Norcross, GA, USA) Pulse sound measurement system (Pulse 9 \& 10 software), equipped with a $3560 \mathrm{C}$ high-frequency module, and a 4138 pressure-field microphone (Brüel \& Kjaer) coupled to the transducer using rubber tubing with the internal dimensions of an adult rat external auditory canal. The sound measurement system permitted linear sound intensity measurements between 0 and $140 \mathrm{~dB}$ (re $20 \mu \mathrm{Pa}$ ) and spectral analysis between $6.5 \mathrm{~Hz}$ and $100 \mathrm{kHz}$. Calibrations were carried out as unweighted linear SPLs; hence, the intensity levels reported in the present experiments represent unweighted measures.

Sound intensities were calibrated in operant test chambers using the Brüel \& Kjaer Pulse system described above, equipped with a Brüel \& Kjaer 4191-L free-field microphone. The sound measurement system so equipped permitted linear sound intensity measurements to be made between 0 and $140 \mathrm{~dB}($ re $20 \mu \mathrm{Pa})$ with spectral analysis between $3.15 \mathrm{~Hz}$ and $40 \mathrm{kHz}$. The microphone was positioned in each test chamber at a location $10 \mathrm{~cm}$ below the lid-mounted speaker, in the approximate location of a rat's head during testing. A cloth bundle approximating the volume of a rat was placed in the test chamber along with the microphone to distort the sound field as it would be by the presence of a rat.

\section{Hearing thresholds}

Acoustic brainstem-evoked response (ABR) thresholds were obtained before loud-sound exposure, immediately after exposure (if exposed) (Table 1, week 1), and at the conclusion of behavioral testing while being treated with the high-dose of vigabatrin (Table 1, week 67). ABR measurements were taken with an Intelligent Hearing Systems (IHS) Smart EP System, running IHS High Frequency Software (version 2.33) and using IHS high-frequency transducers (HFT9911-20-0035, IHS, Miami, FL, USA). For ABR assessment, subjects were anesthetized with an intramuscular ketamine $\mathrm{HCl} /$ xylazine $(24.6 / 3 \mathrm{mg} / \mathrm{kg})$ mixture and placed in a modified stereotaxic head frame inside a sound-attenuation chamber. Acoustic stimuli were presented directly to the entrance of the ear canal. Stainless steel needle electrodes were placed subcutaneously at the vertex and over the bullae with a reference electrode at the occiput. ABR thresholds were obtained for 5-ms-duration clicks and 5-ms-duration tone bursts presented at a rate of $50 / \mathrm{s}$. Tone bursts were gated using an exact Blackman envelope (2.5 ms rise/decay, $0 \mathrm{~ms}$ plateau) and presented in a decreasing intensity series, beginning with levels that elicited distinct evoked potentials. Threshold was indicated by the lowest intensity that produced visually distinct evoked potentials, progressing in 20-, 10-, and 5-dB (re $20 \mu \mathrm{Pa}$ ) steps, from above threshold to near threshold, respectively. Evoked potentials were amplified $\times 200,000$, bandpass filtered $(100-3,000 \mathrm{~Hz})$, and averaged over 1,024 sweeps. Recording epochs comprised the $12 \mathrm{~ms}$ following stimulus onset.

\section{Behavior: initial training}

Subjects were trained and tested using a procedure shown to detect tinnitus in animals (Bauer and Brozoski 2001). All subjects were run in parallel throughout training and testing, i.e., they differed only in their initial exposure to loud sound. Training and testing occurred in individual commercial operant conditioning chambers (Lafayette Instruments, Mod. 80001, Lafayette, IN, USA). The rats were maintained on restricted food intake and trained to lever press for food pellets ( $45 \mathrm{mg}$, formula A/I, Research Diets, New Brunswick, NJ, USA). Diet restriction was individually tailored to each subject, sufficient to produce a minimum of 200 lever presses per session (study average per subject, 2,230) with less than $10 \%$ within-session variation. Supplementary food was given at the conclusion of each session sufficient to maintain body weight above $85 \%$ of normative age-weight values. Five to six sessions were run per week, with each being $60 \mathrm{~min}$ in duration. Operant training required 4 weeks to achieve criterion performance using a variable-interval reinforcement schedule (Table 1 , weeks $2-5$ ). The variable interval schedule had a median value of $20 \mathrm{~s}$. (on average, a food pellet was available after a lever press every $20 \mathrm{~s}$ ), with an upper limit of $30 \mathrm{~s}$ and lower limit of $6 \mathrm{~s}$. The reinforcement schedule was in place continuously throughout every session, including all stimulus presentations. Broad-band noise $(\mathrm{BBN})$ at $60 \mathrm{~dB}$ SPL was presented to each operant chamber via a speaker (Optimus, 40-1219, Tandy), centermounted in each chamber lid (calibration procedure described above). The BBN was constant, except when acoustic test stimuli were presented, at which time it was turned off. Experimental control and data acquisition was accomplished using desktop computers running in-house programs and custom interfaces (Keithley/MetraByte, Cleveland, OH, USA). 
Behavior: the suppression ratio, a running relative measure

In each 1-min period of each session, a suppression ratio $(R)$ was calculated for each subject, using the formula $R=B /(A+B)$, where $A$ was the number of lever presses in the preceding period and $B$ the number of lever presses in the current period. $R$ can vary between 0 and 1: A value of 0 is attained when lever pressing in the current 1 -min period is 0 , a value of 0.5 when lever pressing in the current 1 -min period is equal to that of the previous period, and a value of 1 when lever pressing in the previous period is zero. The runtime control program intervened in the few instances when subjects did not lever press for two or more successive minutes, in which case, $R$ was defined as $0 . R$ provided a running index of behavior and enabled a quantitative comparison between subjects as well as unbiased compilation of group data. With $R$ as the performance measure, each subject contributed equally to group data irrespective of overall response rate. In the present type of experiment, $R$ has additional utility in that it is very sensitive to short-term behavioral effects, such as those that might be produced by presentations of test stimuli, but is very insensitive to long-term behavioral effects, such as those that might be produced by shifts in motivational status, for example, satiation.

\section{Behavior: acclimation to acoustic variation}

Following initial training, ten acoustic test stimuli were introduced using a procedure designed to acclimate subjects to the presentation of acoustic events other than BBN (Table 1, week 6). During stimulus introduction, which extended over six sessions, all behavioral contingencies remained the same as in training. Acoustic stimuli were digitally synthesized (Stanford Research Systems, DS-345, Palo Alto, CA, USA) and presented for $60 \mathrm{~s}$ over the lid-mounted speakers. Stimulus presentations could not occur within $2 \mathrm{~min}$ of one another, or within 2 min of the beginning or end of the session. Two of the ten presentations were always speaker-off periods. The remaining eight presentations were either $\mathrm{BBN}, 10-\mathrm{kHz}$ tones or $20-\mathrm{kHz}$ tones presented at four different intensity levels, randomly ordered, with the intensities extending across the subject's sensitivity range. Each test stimulus intensity level was repeated once within the session . Test stimulus type, i.e., BBN, $10 \mathrm{kHz}$, and $20 \mathrm{kHz}$, varied randomly between sessions, but remained constant within a session. Background sound was off during the test presentations.

\section{Behavior: suppression training}

Suppression training followed stimulus acclimation (Table 1, week 7). In suppression training, the subjects received a 1-s, 0.5-mA foot shock through the grid floor of the test chamber if they lever pressed above a criterion level in speaker-off periods. The purpose of suppression training was twofold: It trained the subjects to listen carefully to their acoustic environment throughout the session because foot shocks could only be avoided if the unpredictable speaker-off periods were detected. Secondly, it trained subjects to discriminate between the speaker-on and speaker-off periods. A single foot shock was given at the end of a speaker-off period if $R \geq 0.1$. When subjects decreased their lever pressing during speaker-off periods so that $R<0.1$, foot shock was avoided. It is important to note that whenever the speaker was on, irrespective of the acoustic signal, lever presses never led to foot shock. Although the majority of subjects achieved criterion-level suppression within two sessions, six suppression-training sessions were given to all subjects. The foot shock contingency during speaker-off periods remained in place throughout the experiment, including the acoustic test sessions described below. In that sense, suppression training was a constant feature of the experimental paradigm, once implemented. On average, subjects received less than one foot shock per month for the remainder of the study. The tandem constant parameters of food reinforcement for lever pressing, and foot shock for speaker-off lever pressing, maintained discrimination behavior in a steady state.

\section{Behavior: acoustic stimulus testing}

The objective of acoustic stimulus testing was to determine the presence of tinnitus using a measure more sensitive than behavior during speaker-off periods. This was provided by discrimination of specific acoustic stimuli. A subject's response to acoustic stimuli is in a large part determined by the subject's experiential history. In the context of the present experiment, a key historical/training factor was sensations associated with speaker-off periods: Subjects without tinnitus should hear nothing with the speaker off, whereas those with tinnitus should hear their tinnitus. In acoustic testing, subjects were challenged with brief periods (60 s) of noise and tones of various intensities. Test stimuli with sensory features resembling tinnitus had no special meaning (i.e., conditioning history) for normal hearing subjects, but for subjects with tinnitus, they would function as a signal for response suppression. That 
is to say, acoustic stimuli with sensory features resembling tinnitus should produce greater suppression in subjects with tinnitus. Using human clinical data as a guide, the exaggerated suppression should be most evident at low- to midintensities of specific test stimuli. As in acclimation, the acoustic stimuli were presented in pseudorandomly scheduled, 60-s test periods.

Previous research (e.g., Bauer and Brozoski 2001) has shown that Long-Evans adult rats unilaterally exposed to loud band-limited noise, as specified above, show evidence of tinnitus when tested with $16-$ to $30-\mathrm{kHz}$ tones, with the clearest evidence obtained using $20-\mathrm{kHz}$ tones. The present experiment tested subjects with BBN, 10-kHz tones, and 20$\mathrm{kHz}$ tones. One of the three stimuli was presented eight times within a session, using four different intensity levels, with each intensity repeated once, for a total of eight $(4 \times 2)$ presentations per session. Only one type of stimulus was tested in a given session, with intensity order randomized within the session. Every test series included two additional, randomly inserted, speaker-off periods. As in acclimation, test presentations and speaker-off periods were $60 \mathrm{~s}$ in duration, separated from one another and the session start and end by a minimum of $2 \mathrm{~min}$ of background sound. The range of test intensity levels depended upon the stimulus and always extended from near hearing threshold to clearly above threshold. Each stimulus (i.e., BBN, 10-kHz tones, and 20$\mathrm{kHz}$ tones) was tested over a minimum of five sessions, with stimulus type randomized across sessions. The background sound was off when the acoustic stimuli were present, as well as in speakeroff periods. The food reinforcement schedule was in place throughout, whereas the foot shock was criterion-dependent upon speaker-off lever pressing. Exposed and unexposed subjects were treated identically and tested in parallel, five to six sessions per week, for 3 weeks. Individual subject and group stimulus discrimination functions were derived from test stimulus suppression ratio data. Initial discrimination training occurred in weeks 8-10 and discrimination testing with derivation of psychophysical functions occurred in weeks 11-13 (Table 1).

\section{Behavior: subject selection}

Based on the psychophysical performance of their final ten test sessions, six subjects displaying the best evidence of tinnitus were selected from the exposed group and six subjects displaying the least evidence of tinnitus were selected from the unexposed group. Evidence of tinnitus was determined by the divergence of individual $20-\mathrm{kHz}$ discrimination functions from the group average function: Tinnitus was indicated by a function downshift (i.e., enhanced suppression) and lack of tinnitus by the absence of a downshift. At the conclusion of predrug testing, approximately 3 months after exposure, the subjects were returned to unrestricted food access and maintained in their home cages for 10 months without further training or testing. Previous experience with this animal model has shown that the psychophysical evidence of tinnitus often becomes more pronounced with increased postexposure intervals (Bauer and Brozoski 2001; Turner et al. 2006).

\section{Drug testing}

The effect of vigabatrin on the psychophysical performance of exposed and unexposed subjects was tested using an ascending-dose series, beginning 10 months after predrug testing. Vigabatrin (Sabril, lot 5485, Aventis Pharma, Kent, UK) powder was dissolved in tap water at either $0,0.473$, or $0.946 \mathrm{mg} / \mathrm{ml}$, depending on the dose condition. Fresh solutions were made daily and given to subjects in 100-ml graduated cylinders with drinking spouts. The drug solutions were substituted for the subjects' normal drinking water and made continuously available, except in the operant test chambers. Average daily liquid consumption for all subjects over the course of the experiment was $35.7 \mathrm{ml}$, resulting in average drug dose levels of $0,30.3(\mathrm{SD}=12.5)$, and $80.9 \mathrm{mg} \mathrm{kg}^{-1}$ day $^{-1}(\mathrm{SD}=25.7)$ for successive test series. Each dose test series required 16 to 18 days to complete (Table 1 , weeks 59-67). Drug testing was followed by a 7-week washout period (Table 1, weeks 68-74), at the end of which a final test series was run without the drug $\left(0 \mathrm{mg} \mathrm{kg}^{-1} \mathrm{day}^{-1}\right)$ (Table 1 , weeks $\left.75-77\right)$. Therefore, the effect of vigabatrin on psychophysical performance (all stimuli at all intensities) was tested in four successive series, of $0,30,81$, and 0 (washout) $\mathrm{mg}$ $\mathrm{kg}^{-1}$ day $^{-1}$.

The oral route of drug administration via drinking water and dose levels were derived from the study of Gleich et al. (2003), which documented the effect of vigabatrin on sound gap detection in gerbils. While drinking-water administration of the drug resulted in some intersubject dose variation, several important benefits accrued: (a) Drug administration was benign, eliminating the potential disruption of behavior in daily test sessions; (b) rats on a restricted diet drink a reasonably consistent volume from day to day; therefore, the subjects attained a consistent chronic dose, similar to the dose regimen recommended for humans; and (c) chronic drug administration was maintained without the attendant risks of systemic infection, often associated with repeated parenteral 
injections, or gastric/pulmonary distress, associated with oral gavage.

\section{Data analysis}

All data were entered into spreadsheets. For inclusion in statistical analysis, individual-subject psychophysical data sets had to pass two quality filters: (a) There had to be a minimum of 200 total lever presses in the session, and (b) the average suppression ratio during nontest periods (i.e., during background BBN) had to be at least 0.4. The first criterion insured that a sufficient number of responses were present for meaningful suppression ratios to be determined for 1-min periods. The second criterion insured that responses were distributed evenly across the session so that discrimination of the randomly scheduled test stimuli was equitably measured regardless of when they occurred in the session. The quality filters were automatically applied to all data by formulas residing in each spreadsheet data record. Descriptive and inferential statistical analyses and graphic depictions were done using Excel (Professional Edition, 2003, Microsoft, Redmond, WA, USA). Two-factor mixed ANOVAs were used to compare exposed-unexposed performance at each dose level within each test stimulus condition: Noiseexposed vs unexposed was the independent group comparison and stimulus intensity level was the repeated-measures comparison.

\section{RESULTS}

Noise exposure and hearing thresholds

Noise exposure elevated ABR thresholds of exposed ears a maximum of $47 \mathrm{~dB}$ at $16 \mathrm{kHz}$, immediately after exposure (Fig. 1A). Thresholds of unexposed ears were unaffected. At the conclusion of predrug behavioral testing, approximately 4 months after exposure, the ABR thresholds of exposed ears were elevated by a maximum of $8 \mathrm{~dB}$ above those of the left ear of the unexposed subjects in the range of 16$20 \mathrm{kHz}$ (Fig. 1B). ABR thresholds of the unexposed (right) ears in both groups were normal, both immediately after exposure and at the conclusion of predrug testing.

\section{Vigabatrin and psychophysical performance}

Psychophysical evaluation of the 12 selected subjects, six exposed with prior evidence of tinnitus and six unexposed with no evidence of tinnitus, resumed 10 months after the conclusion of predrug training and testing. After 2 weeks of retraining, the subjects were tested for tinnitus without the drug $\left(0 \mathrm{mg} \mathrm{kg}^{-1}\right.$ day $\left.^{-1}\right)$.
Testing required 3 weeks. Exposed subjects demonstrated good evidence of tinnitus with a significant downshift in their 20-kHz-tone discrimination function (Fig. 2A), relative to unexposed subjects $\left(F_{1,40}=5.199, p=0.028\right)$. As expected, there were no significant differences between exposed and control performance when tested with noncritical stimuli (BBN: Fig. 2B, $F_{1,40}=1.007, p=0.322 ; 10-\mathrm{kHz}$ tones: Fig. $\left.2 \mathrm{C}, F_{1,40}=0.266, p=0.609\right)$. The downshifted discrimination function of the exposed subjects indicated that the $20-\mathrm{kHz}$ tones resembled their subjective sensation perceived during "speaker-off" or "silent" periods more closely than it did for unexposed subjects (see above). The assumption is that the presence of tinnitus affects the perception of the acoustic environment; in other words, "silence" for exposed subjects resembles a $20-\mathrm{kHz}$ tone. Note
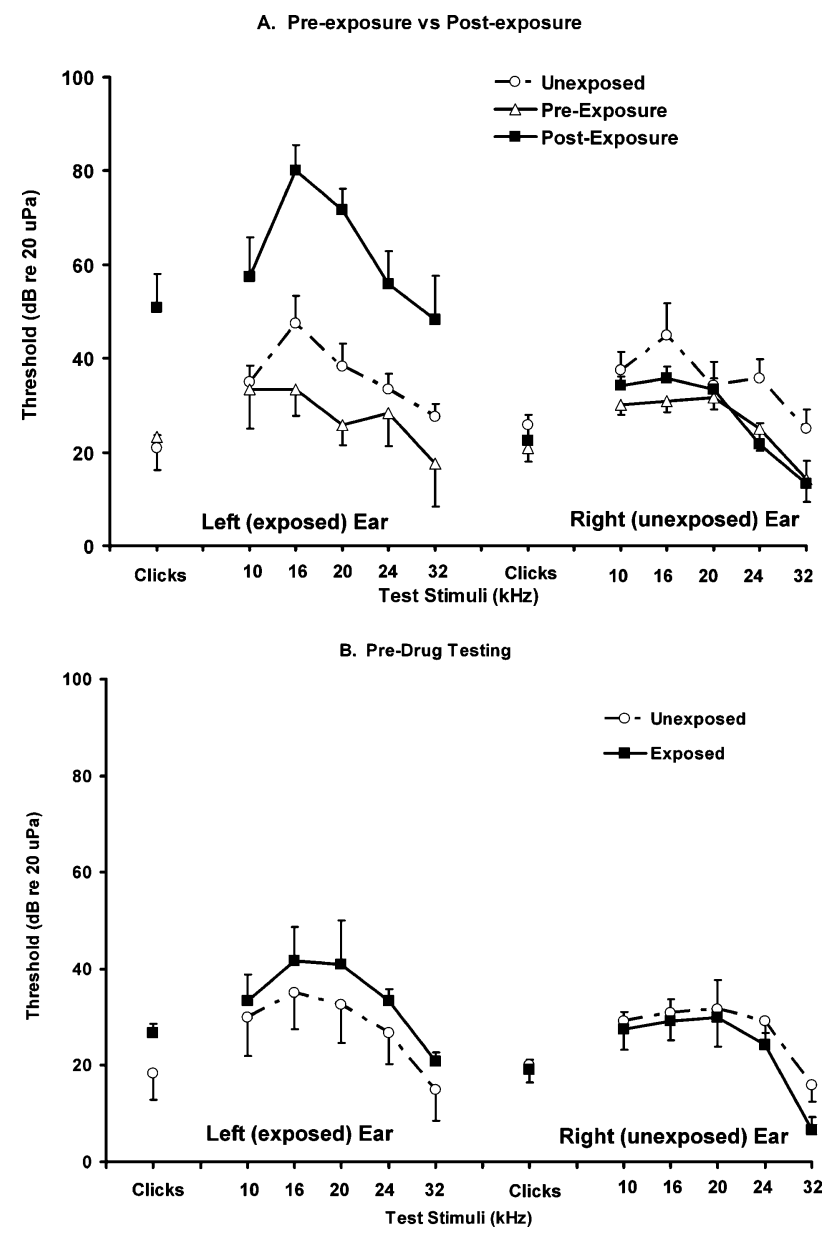

FIG. 1. Hearing thresholds, as indicated by $A B R$, obtained immediately before and after band-limited noise exposure $(\mathbf{A})$ and at the conclusion of predrug training, approximately 4 months after exposure (B). The experimental subjects were exposed once unilaterally (left ear) for 60 min while anesthetized, using a speaker driver attached to a cone-shaped speculum that fit tightly into the auditory canal. Peak stimulus intensity, centered at $16.13 \mathrm{kHz}$, was $120 \mathrm{~dB}$ (SPL), with an approximately linear decay to ambient levels at 8 and $28 \mathrm{kHz}$. 


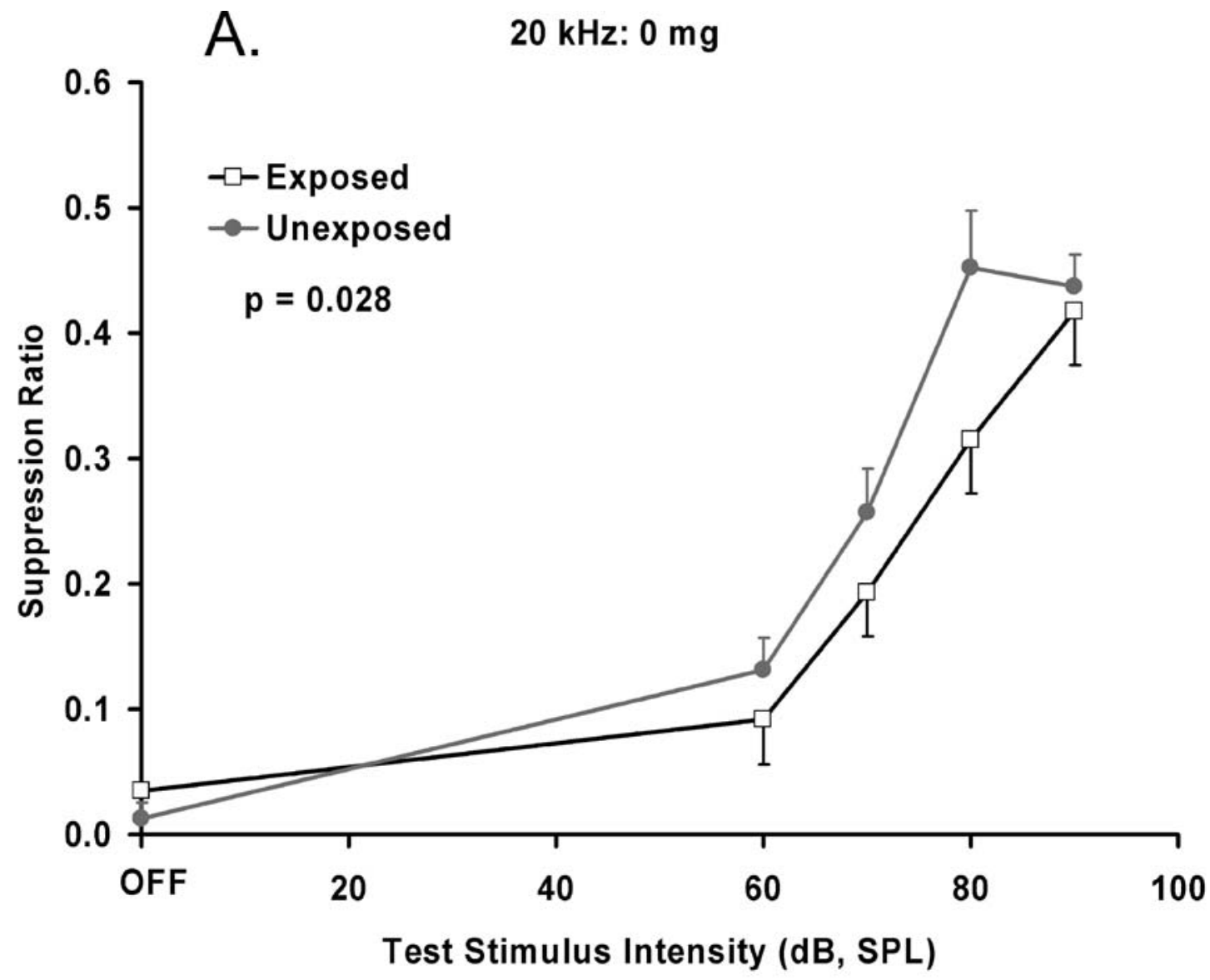

B. BBN: $0 \mathrm{mg}$

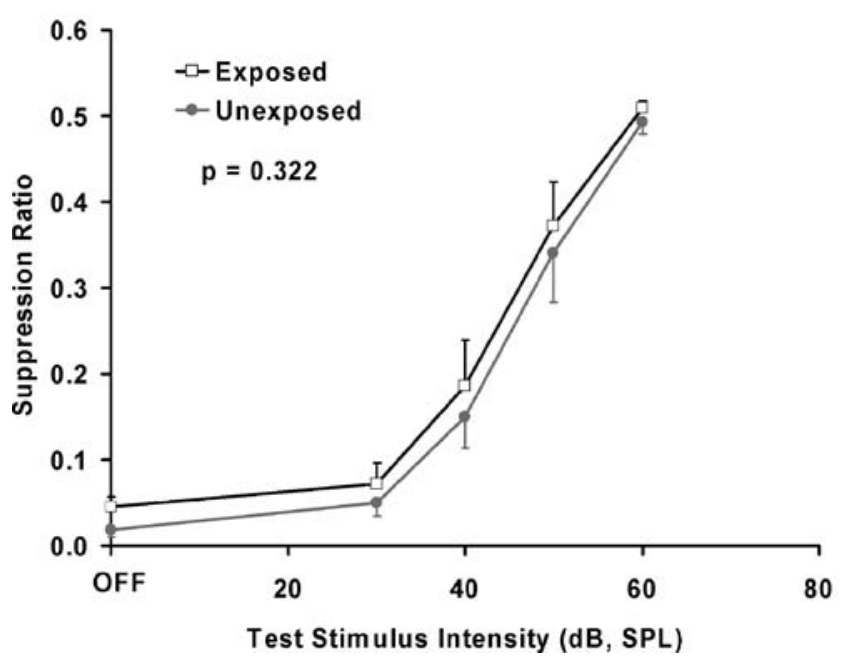

C.

$10 \mathrm{kHz}: 0 \mathrm{mg}$

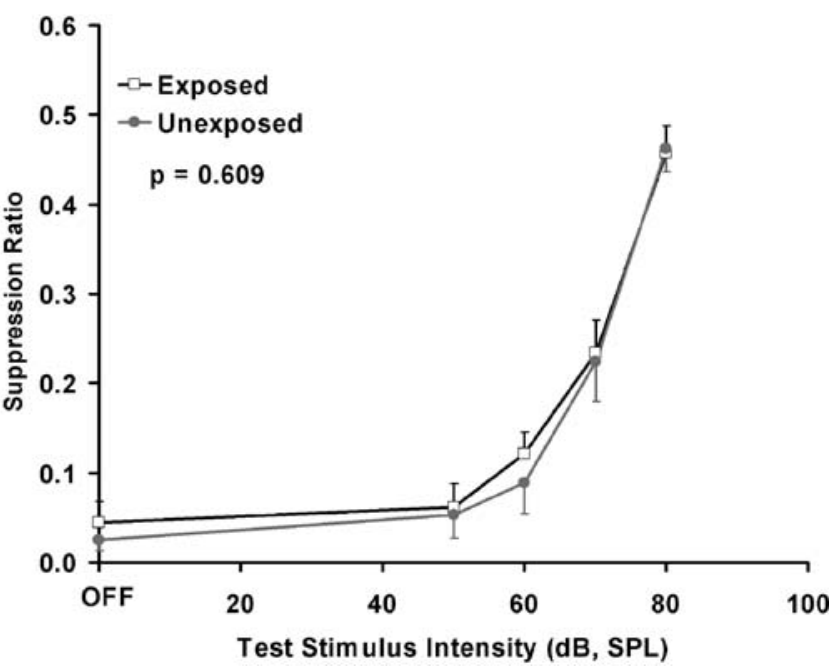

FIG. 2. Initial psychophysical performance at $0 \mathrm{mg} \mathrm{kg}^{-1} \mathrm{day}^{-1}$. Down shift of the exposed group's 20-kHz discrimination function (A), with respect to the unexposed group's function, indicated the presence of tinnitus with characteristics resembling a 20-kHz tone. Discrimination of control stimuli (B and C) was not affected. Suppression ratio is a relative performance measure, 0 corresponding to no lever presses and 0.5 corresponding to a lever-press rate equivalent to baseline. Test stimulus presentations were $60 \mathrm{~s}$ in duration, randomly inserted into sessions of background sound (BBN, $60 \mathrm{~dB}, \mathrm{SPL}$; turned off during test stimulus presentations). N=6/group. 

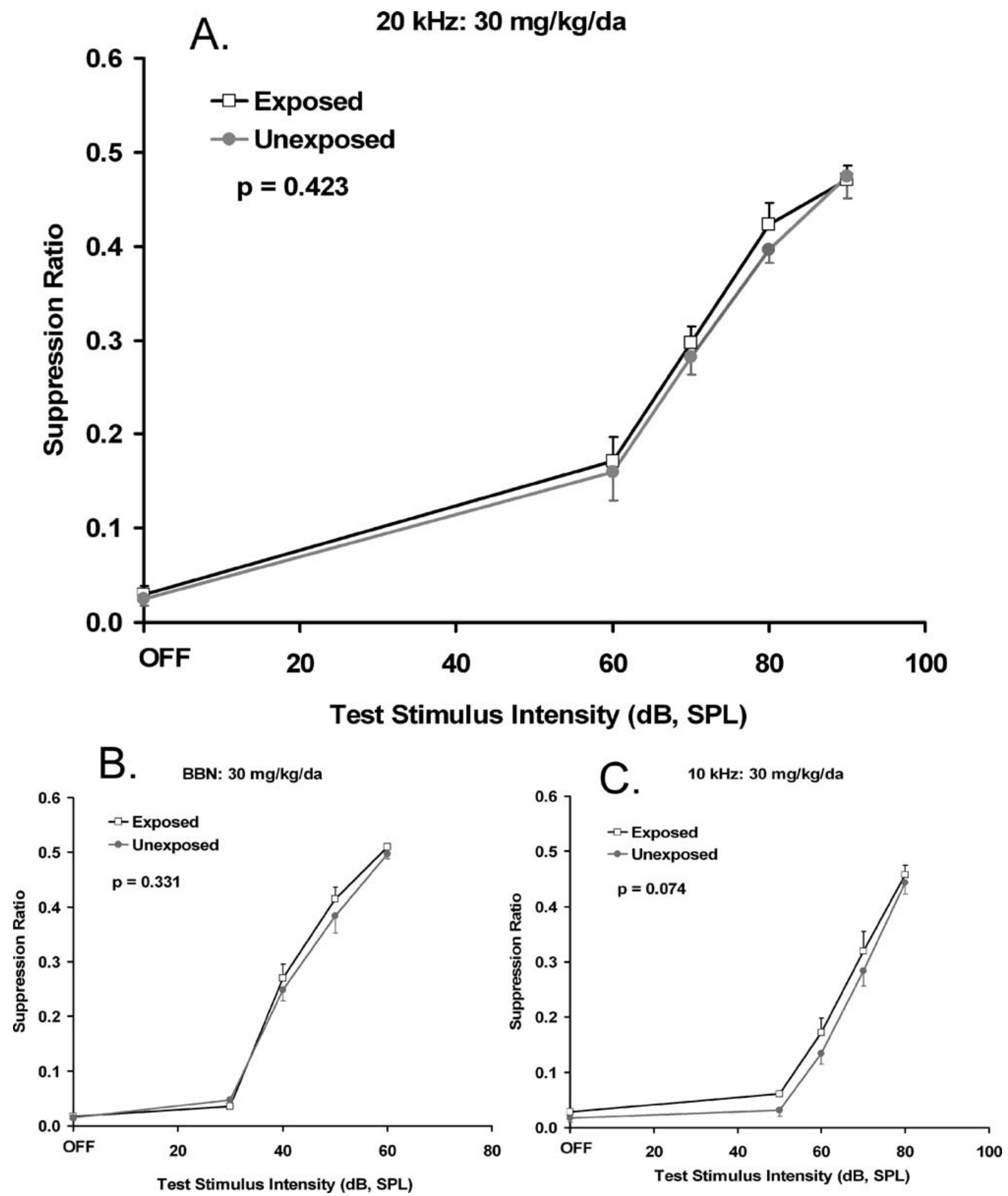

FIG. 3. Psychophysical functions obtained with all subjects treated with vigabatrin at $30.27 \mathrm{mg} / \mathrm{kg}$ average daily dose. Subjects and test parameters are as described in Figure 2. There was no significant difference in discrimination performance between the exposed and unexposed subjects.

that all subjects were suppression-trained to stop lever pressing $(R \approx 0)$ during speaker-off periods, and that acoustic conditions (and all other treatment conditions) were identical for all subjects. 

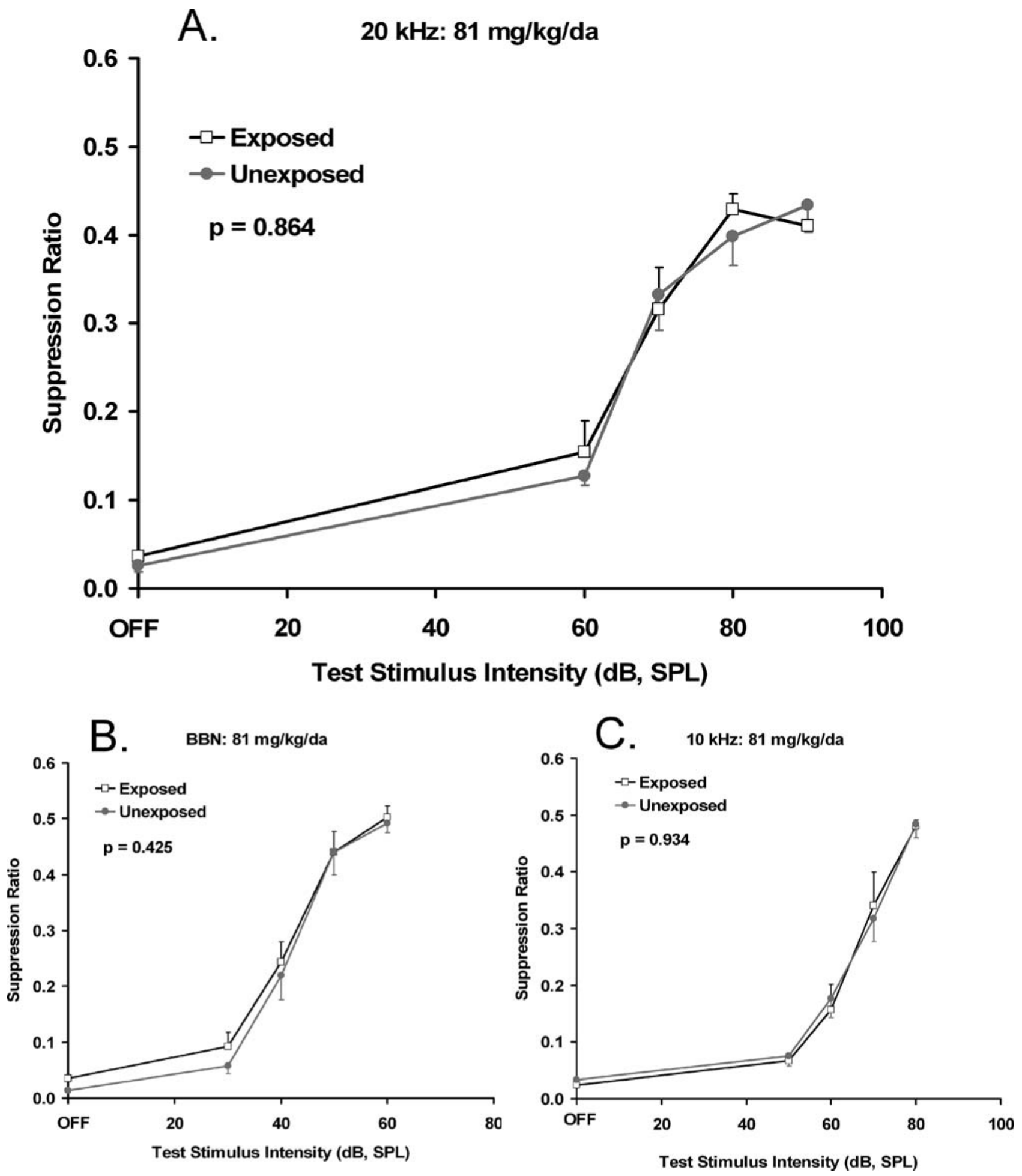

FIG. 4. Psychophysical functions obtained with all subjects treated with vigabatrin at $80.96 \mathrm{mg} / \mathrm{kg}$ average daily dose. Subjects and test parameters are as described in Figure 2. There was no significant difference in discrimination performance between the exposed and unexposed subjects.

After completion of data collection at the $0-\mathrm{mg}$ $\mathrm{kg}^{-1}$ day $^{-1}$ dose, all subjects were given continuous access (except within the test chamber) to a vigabatrin solution $(0.473 \mathrm{mg} / \mathrm{ml})$ substituted for their normal drinking water. The drug concentration resulted in an average dose of $30.27 \mathrm{mg} \mathrm{kg}^{-1}$ day $^{-1}$ $(\mathrm{SD}=12.51)$ (referred to henceforth as the $30-\mathrm{mg}$ dose). Three days after the start of drug administra- 

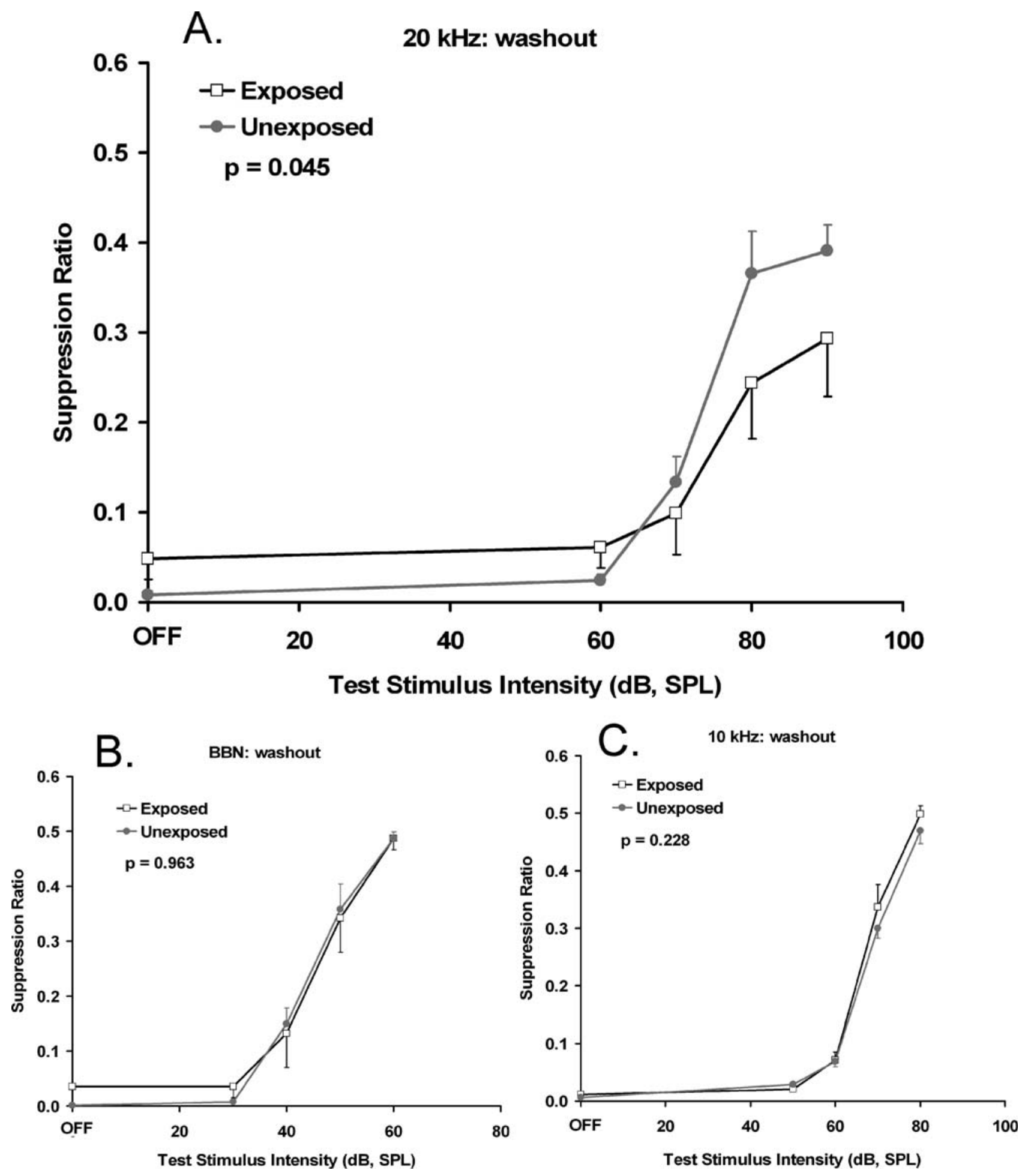

FIG. 5. Psychophysical functions obtained after a 7-week washout period without the drug. Subjects and test parameters are as described in Figure 2. The significant difference between exposed and unexposed subjects returned for 20-kHz-tone discrimination.

tion, psychophysical testing resumed and required 3 weeks to complete. Subjects consumed vigabatrin throughout this 2-week period. At the 30-mg dose, there was no psychophysical evidence of tinnitus: Discrimination performance, for all stimuli, was identical for both exposed and unexposed groups (Fig. 3). Immediately after concluding the 30-mgdose test period, the drug solution concentration was doubled to $0.946 \mathrm{mg} / \mathrm{ml}$. Four days after the concentration increment, psychophysical testing re- 


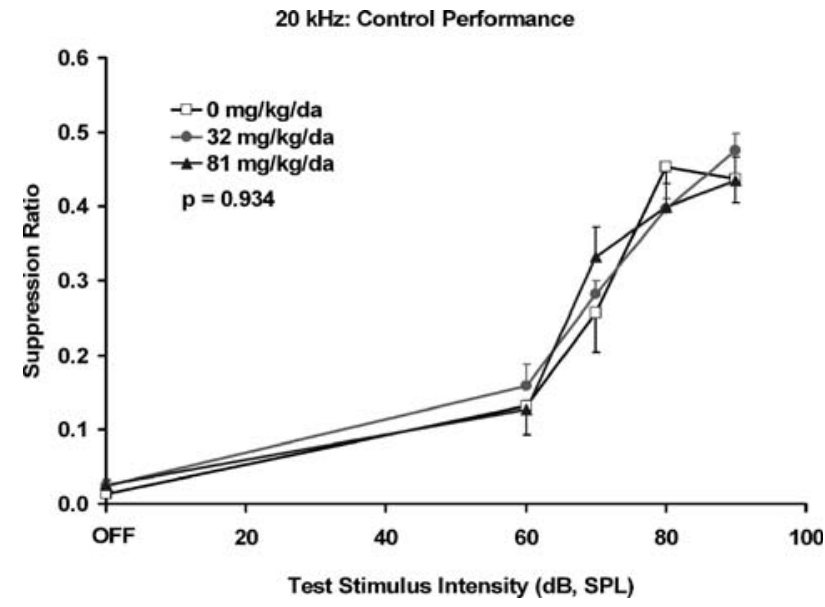

FIG. 6. Twenty-kilohertz discrimination functions of unexposed subjects at the three dose levels of vigabatrin tested. Test parameters are as described in Figure 2. There was no significant effect of drug treatment on discrimination performance.

sumed, and continued for 3 weeks, during which the average dose consumed was $80.96 \mathrm{mg} \mathrm{kg}^{-1}$ day $^{-1}$ (henceforth referred to as the 81-mg dose). As in the case of the lower dose, there was no psychophysical evidence of tinnitus at the higher dose: Exposed and unexposed subjects showed equivalent discrimination of all stimuli (Fig. 4). Neither drug dose negatively affected the general performance of either group, as indicated by session total lever presses.

At the conclusion of the 81-mg-dose series, vigabatrin was removed from the animals' drinking water and they were maintained in their home cages for 7 weeks. At the end of this 7-week washout period, psychophysical testing resumed with the animals off the drug. Significant evidence of tinnitus was again apparent in the exposed subjects. The 20-kHz-tone discrimination function of exposed subjects was downshifted with respect to controls (Fig. 5A; $F_{1,40}=4.286$, $p=0.045)$, whereas there was no difference between groups for BBN discrimination (Fig. $5 \mathrm{~B} ; F_{1,40}=0.002$, $p=0.963$ ) or $10-\mathrm{kHz}$-tone discrimination (Fig. 5C; $\left.F_{1,40}=1.496, p=0.228\right)$.

Examination of the unexposed group's 20-kHztone discrimination at the three dose levels tested $(0$, 30.27 , and $80.96 \mathrm{mg} \mathrm{kg}^{-1}$ day $^{-1}$ ) showed no effect of vigabatrin on performance (Fig. 6; $F_{2,60}=0.067$, $p=0.934)$. The therapeutic effect of vigabatrin on tinnitus observed at 30.27 and $80.96 \mathrm{mg} \mathrm{kg}^{-1}$ day $^{-1}$ therefore cannot be attributed to a control-group effect. Midrange (70 dB, SPL) $20-\mathrm{kHz}$ discrimination performance of the exposed group across the three vigabatrin dose levels tested is shown in Figure 7. Performance below the control group performance range (Fig. 7, shaded area) indicated the presence of tinnitus. Both 30 and $81 \mathrm{mg} \mathrm{kg}^{-1}$ day $^{-1}$ were effective in elevating the exposed group's perfor- mance into the control range, with the best improvement obtained with $81 \mathrm{mg} \mathrm{kg}^{-1}$ day $^{-1}$.

\section{DISCUSSION}

A wide variety of drugs have been tested as potential tinnitus therapeutics, with generally negative, and a few mixed, results (Dobie 1999). Reports of successful tinnitus treatment using drugs of unknown specificity and unknown mechanisms of action (Jastreboff et al. 1997) may be therapeutically informative but cannot be used to advance the neuroscience of tinnitus. Both basic science and clinical research indicate that the GABA neurotransmitter system is a reasonable focus for tinnitus research. The GABA analog gabapentin has been tested in both an animal model (Bauer and Brozoski 2001) and a controlled clinical trial (Bauer and Brozoski 2006), with partial success. Unfortunately, although gabapentin is a GABA analog, its mechanism of action is still uncertain (Lanneau et al. 2001). Vigabatrin is a specific GABA agonist with a well-characterized mechanism of action: suicide blockade of GABA transaminase (GABA-T) (French 1999; Guberman 1996; Richens 1991). That central GABA levels are elevated by vigabatrin has been well documented in animal (Behar and Boehm 1994; de Graaf et al. 2006) and human (Mattson et al. 1995; Petroff and Rothman 1998) studies. More importantly, the present research demonstrated that vigabatrin treatment effectively eliminated the psychophysical evidence of chronic tinnitus in an animal model.

20 kHz @ 70 dB (SPL)

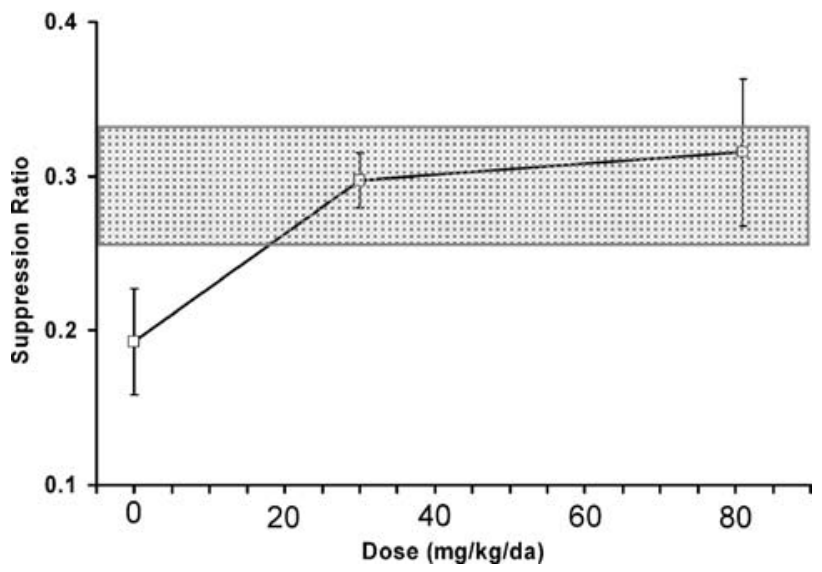

FIG. 7. Vigabatrin dose function for exposed subjects tested at 20 $\mathrm{kHz}, 70 \mathrm{~dB}(\mathrm{SPL})$, i.e., midrange intensity. Tinnitus was indicated by the decrease of $20-\mathrm{kHz}$ responding below control levels, at $0 \mathrm{mg}$, whereas elevation of responding to within the control-group range, shown as the shaded area (mean \pm 1 standard error), indicated the alleviation of tinnitus. 
The results of the present study were consistent with a specific hypothesis about the pathophysiology of chronic acoustic-trauma-induced tinnitus: loss of inhibition in the central auditory pathway (Brozoski et al. 2002; Diesch et al. 2004; Eggermont and Roberts 2004; Salvi and Ahroon 1983) and decreased GABA function as a likely component of that decreased inhibition. From this hypothesis it was predicted that the elevation of central GABA levels, using a drug such as vigabatrin, would effectively counteract tinnitus. The results of the present experiment were in agreement with these hypotheses. Using the animal model described, vigabatrin, at moderate dose levels completely eliminated the psychophysical evidence of tinnitus in rats. This therapeutic effect of vigabatrin was specific in that the auditory discrimination performance of control subjects was unaffected by the drug (Fig. 6), and it was reversible, disappearing after a washout period (Fig. 5). Kinetic studies of vigabatrin using rats have shown that, following a single large dose $(200 \mathrm{mg} / \mathrm{kg})$, significant GABA-T inhibition was evident within $4 \mathrm{~h}$ of treatment, with maximum inhibition attained $24 \mathrm{~h}$ after treatment (Valdizan et al. 1999). The same study showed that after chronic treatment with vigabatrin for 8 days, rapid recovery from inhibition was evident $24 \mathrm{~h}$ after the cessation of treatment, and virtual complete recovery of GABA-T function was evident $72 \mathrm{~h}$ after the cessation of treatment (Valdizan et al. 1999).

Vigabatrin has been shown to facilitate the auditory performance of old gerbils with a performance deficit (Gleich et al. 2003) in a sound-gap detection paradigm. This finding is not entirely surprising given that GABA had been shown to affect the temporal performance of neurons in the cochlear nucleus of rats (Backoff et al. 1997). Results of the present study indicate that enhancing central GABA levels significantly affects tonic auditory processes as well. This finding is not entirely surprising either, given the neurophysiological evidence: Direct application of GABA and GABA agonists to spontaneously active neurons in the cochlear nucleus has been shown to decrease their discharge rate, whereas the application of GABA antagonists had the opposite effect (Backoff et al. 1999). The age-related loss of GABA neurons and markers has been documented in the anterior brainstem of rats (Caspary et al. 1995), whereas chronic salicylate treatment, well known to produce tinnitus in animals (Bauer et al. 1999a) and humans (Mongan et al. 1973), produced a down regulation of GABA-A receptors (Bauer et al. 2000).

Several animal models of tinnitus have been developed since the seminal work of Jastreboff and colleagues (Jastreboff et al. 1988). The present model lends itself well to repeated dose testing and exam- ination of tinnitus over long time periods, where aging factors may enhance the tinnitus (Brozoski et al. 1996), hence the long postexposure interval used in the present study. The present model has also been cross-validated using an independent sound-gap method (Turner et al. 2006) and has been successfully applied to both chinchillas (Brozoski et al. 2002) and mice (Prosen and May 2005). Despite the strengths of the present model, it is time consuming, with extensive training and repeated measurement required to detect tinnitus. Other animal models of tinnitus have better efficiency and may reflect features of the disorder not revealed by the present model (for reviews, see Bauer and Brozoski in press; Bauer 2003; Moody 2004). The present model is also typically applied in the context of group treatment effects, whereas other models have been applied to individual subject data, as well as group results. Because it is likely that individual subjects exposed to a common tinnitus-induction procedure, such as loud sound, develop tinnitus to varying degrees, methods that detect tinnitus in individual subjects are useful. Nevertheless, despite their particular features, all animal tinnitus models rely on some type of behavioral measurement to determine the perception of sound. As such, all models will be affected by extraneous factors other than tinnitus, for example hearing sensitivity and sensory-motor status, to mention two. The present study was not exempt from contending with extraneous factors, one of which was drug dose variation between subjects because vigabatrin was administered in their drinking water. However the present model's reliance on group data and repeated measurement enabled many extraneous factors to be statistically controlled as random error. This would include the fluctuation of tinnitus loudness within individual subjects over time. Human clinical data suggest that periodic variation in tinnitus loudness is to be expected, with two large data sets indicating better than $47 \%$ of surveyed patients reporting daily loudness fluctuations (Meikle et al. 2004). Repeated measurement and group data analysis can mitigate potential errors of interpretation stemming from tinnitus fluctuation.

The neurophysiology of chronic tinnitus may be as simple as inappropriately elevated spontaneous neural activity in the auditory pathway, perhaps focal to the brainstem. Although this hypothesis may be too simple to accommodate all the evidence, it generates testable hypotheses that can be used to advance the neuroscience of tinnitus. Many questions remain to be answered. The cascade of events between auditory insult and elevation of spontaneous activity is unknown. In addition to GABA, what other neurotransmitters and neuromodulators are involved in 
the process? Where does the dysfunction initially develop in the nervous system? When, or how, does spontaneous neural activity become audible? Many neurons are spontaneously active throughout the auditory pathway of intact subjects, most of whom likely do not have tinnitus. Spontaneous activity increases in general may not be as important as the specific neurons involved, their functional role in auditory processing, and their location in the system. Finally, the persistence and durability of tinnitus must be explained: In both animal (Bauer et al. 2001) and human studies (Vernon 1977), chronic tinnitus appears to be, for the most part, permanent, increasing with age, and resistant to treatment. Understanding the neuroscience of tinnitus is a prerequisite to improving treatment.

\section{ACKNOWLEDGEMENTS}

This work was supported by NIDCD RO1 DC4830-04.

\section{REFERENCES}

Backoff PM, Palombi PS, CASPary DM. Glycinergic and GABAergic inputs affect short-term suppression in the cochlear nucleus. Hear. Res. 110:155-163, 1997.

Backoff PM, Shadduck Palombi P, Caspary DM. Gammaaminobutyric acidergic and glycinergic inputs shape coding of amplitude modulation in the chinchilla cochlear nucleus. Hear. Res. 134:77-88, 1999.

BAUER CA. Animal models of tinnitus. Otolaryngol. Clin. North Am. 36:267-285, 2003.

BaUer CA, Brozoski TJ. Assessing tinnitus and prospective tinnitus therapeutics using a psychophysical animal model. J. Assoc. Res. Otolaryngol. 2:54-64, 2001.

Bauer CA, Brozoski TJ. Effect of gabapentin on the sensation and impact of tinnitus. Laryngoscope 116:675-681, 2006.

Bauer C, Brozoski T. Tinnitus: theories, mechanisms and treatments. In: Webster D, Popper A, and Fay R (eds) Auditory Trauma, Protection, and Treatment. New York, Springer-Verlag, in press, Preprint available online: http://www.jaropreprint.org

Bauer CA, Brozoski TJ, Rojas R, Boley J, Wyder M, Caspary DM. The effects of salicylate on conditioned suppression behavior and receptor pharmacology in the inferior colliculus of the LongEvans rat. St. Petersburg, Association for Research in Otolaryngology, 1998.

Bauer CA, Brozoski TJ, Rojas R, Boley J, Wyder M. Behavioral model of chronic tinnitus in rats. Otolaryngol. Head Neck Surg. 121:457-462, 1999a.

Bauer CA, McMasters Dl, Gaines A, Herr LA, Brozoski TJ. Behavioral evidence of chronic tinnitus in rats after unilateral noise trauma. St. Petersburg, Association for Research in Otolaryngology, 1999b.

Bauer CA, Brozoski TJ, Holder TM, Caspary DM. Effects of chronic salicylate on GABAergic activity in rat inferior colliculus. Hear. Res. 147:175-182, 2000.

Behar KL, Boehm D. Measurement of GABA following GABAtransaminase inhibition by gabaculine: a $1 \mathrm{H}$ and 31P NMR spectroscopic study of rat brain in vivo. Magn. Reson. Med. 31:660-667, 1994.
Brozoski TJ, Bauer CA. The effect of dorsal cochlear nucleus ablation on tinnitus in rats. Hear. Res. 206:227-236, 2005.

Brozoski TJ, Wyder M, Bauer CA. An animal model of tinnitus that reflects some of the qualitative features and the persistence of the disorder. Neurosci Abstr 22:1821, 1996.

Brozoski TJ, Bauer CA, Caspary DM. Elevated fusiform cell activity in the dorsal cochlear nucleus of chinchillas with psychophysical evidence of tinnitus. J. Neurosci. 22:2383-2390, 2002.

Caspary DM, Milbrandt JC, Helfert RH. Central auditory aging: GABA changes in the inferior colliculus. Exp. Gerontol. 30: 349-360, 1995.

Caspary DM, Holder TM, Hughes LF, Milbrandt JC, McKernan RM, NARITOKU DK. Age-related changes in GABA(A) receptor subunit composition and function in rat auditory system. Neuroscience 93:307-312, 1999.

CoOper JC, JR. Health and nutrition examination survey of 1971-75: part II. Tinnitus, subjective hearing loss, and well-being. J. Am. Acad. Audiol. 5:37-43, 1994.

Davis A, El Refaie A. Epidemiology of tinnitus. In: Tyler RS (ed) Tinnitus Handbook. San Diego, Singular, pp. 1-23, 2000.

de Graaf RA, Patel AB, Rothman DL, Behar KL. Acute regulation of steady-state GABA levels following GABA-transaminase inhibition in rat cerebral cortex. Neurochem. Int. 48:508-514, 2006.

Diesch E, Struve M, Rupp A, Ritter S, Hulse M, Flor H. Enhancement of steady-state auditory evoked magnetic fields in tinnitus. Eur. J. Neurosci. 19:1093-1104, 2004.

Dobie RA. A review of randomized clinical trials in tinnitus. Laryngoscope 109:1202-1211, 1999.

Eggermont JJ, Roberts LE. The neuroscience of tinnitus. Trends Neurosci. 27:676-682, 2004.

French JA. Vigabatrin. Epilepsia 40(Suppl 5):S11-S16, 1999.

Gleich O, Hamann I, Klump GM, Kittel M, Strutz J. Boosting GaBA improves impaired auditory temporal resolution in the gerbil. Neuroreport 14:1877-1880, 2003.

Guberman A. Vigabatrin. Can. J. Neurol. Sci. 23:S13-S17, 1996.

Guitton MJ, Pujol R, Puel JL. m-Chlorophenylpiperazine exacerbates perception of salicylate-induced tinnitus in rats. Eur. J. Neurosci. 22:2675-2678, 2005.

Heffner HE, Koay G. Tinnitus and hearing loss in hamsters (Mesocricetus auratus) exposed to loud sound. Behav. Neurosci. 119:734-742, 2005.

Jastreboff PJ. Tinnitus as a phantom perception: theories and clinical implications. In: Vernon JA and Moller AR (eds) Mechanisms of Tinnitus. Needham Heights, Allyn \& Bacon, pp. 73-94, 1995.

Jastreboff PJ, Brennan JF, Coleman JK, Sasaki CT. Phantom auditory sensation in rats: an animal model for tinnitus. Behav. Neurosci. 102:811-822, 1988.

Jastreboff PJ, Zhou S, Jastreboff MM, Kwapisz U, Gryczynska U. Attenuation of salicylate-induced tinnitus by Ginkgo biloba extract in rats. Audiol. Neurootol. 2:197-212, 1997.

Kaltenbach JA, Heffner HE. Spontaneous activity in the dorsal cochlear nucleus of hamsters tested behaviorally for tinnitus. Association for Research in Otolaryngology, vol. abstract\#182. St. Petersburg, Association for Research in Otolaryngology, 1999.

Kaltenbach JA, Zacharek MA, Zhang J, Frederick S. Activity in the dorsal cochlear nucleus of hamsters previously tested for tinnitus following intense tone exposure. Neurosci. Lett. 355:121-125, 2004.

Lanneau C, Green A, Hirst WD, Wise A, Brown JT, Donnier E, Charles KJ, Wood M, Davies CH, Pangalos MN. Gabapentin is not a GABAB receptor agonist. Neuropharmacology 41:965975, 2001.

Lobarinas E, Sun W, Cushing R, Salvi R. A novel behavioral paradigm for assessing tinnitus using schedule-induced polydipsia avoidance conditioning (SIP-AC). Hear. Res. 190:109114, 2004. 
Mattson RH, Petroff OA, Rothman D, Behar K. Vigabatrin: effect on brain GABA levels measured by nuclear magnetic resonance spectroscopy. Acta Neurol. Scand. Suppl. 162:27-30, 1995.

Meikle MB, Creedon TA, Griest SE. Tinnitus Archive, http:// www.tinnitusArchive.org/ (online), 2004.

Milbrandt JC, Albin RL, Turgeon SM, Caspary DM. GabaA receptor binding in the aging rat inferior colliculus. Neuroscience 73:449-458, 1996.

Mongan E, Kelly P, Nies K, Porter WW, Paulus HE. Tinnitus as an indication of therapeutic serum salicylate levels. JAMA 226:142145, 1973.

Moody DB. Animal models of tinnitus. In: Snow JB, Jr. (ed) Tinnitus: Theory and Management. Hamilton, BC Decker, pp. 80-95, 2004.

Petroff OA, Rothman DL. Measuring human brain GABA in vivo: effects of GABA-transaminase inhibition with vigabatrin. Mol. Neurobiol. 16:97-121, 1998.

Prosen C, MAY B. Behavioral and electrophysiological assessment of tinnitus in a mouse model, Association for Research in Otolaryngology, vol. 28. ARO abstracts 319 volume 28, 2005. New Orleans, Association for Research in Otolaryngology, 2005.

Richens A. Pharmacology and clinical pharmacology of vigabatrin. J. Child Neurol. Suppl 2:S7-S10, 1991.

Salvi RJ, Ahroon WA. Tinnitus and neural activity. J. Speech Hear. Res. 26:629-632, 1983
Suneja SK, Potashner SJ, Benson CG. Plastic changes in glycine and GABA release and uptake in adult brain stem auditory nuclei after unilateral middle ear ossicle removal and cochlear ablation. Exp. Neurol. 151:273-288, 1998a.

Suneja SK, Potashner SJ, Benson CG. Plastic changes in glycine and GABA release and uptake in adult brain stem auditory nuclei after unilateral middle ear ossicle removal and cochlear ablation. Exp. Neurol. 151:273-288, 1998b.

Szczepaniak WS, Moller AR. Evidence of neuronal plasticity within the inferior colliculus after noise exposure: a study of evoked potentials in the rat. Electroencephalogr. Clin. Neurophysiol. 100:158-164, 1996.

Turner JG, Brozoski TJ, Bauer CA, Parrish JL, Myers K, Hughes LF, Caspary DM. Gap detection deficits in rats with tinnitus: a potential novel screening tool. Behav. Neurosci. 120:188-195, 2006.

Valdizan EM, Garcia AP, Armijo JA. Time course of the GABAergic effects of vigabatrin: is the time course of brain GABA related to platelet GABA-transaminase inhibition? Epilepsia 40:10621069, 1999.

Vernon J. Attempts to relieve tinnitus. J. Am. Audiol. Soc. 2:124131, 1977

WiLLotT JF, Lu SM. Noise-induced hearing loss can alter neural coding and increase excitability in the central nervous system. Science 216:1331-1334, 1982. 